\title{
Investigation on Surface Insulation Strength of Machinable Ceramic Material under Pulsed Voltage in Vacuum*
}

\author{
Guan-Jun ZHANG*1, Wen-Bin ZHAO*1, Xin-Pei MA*2, Guang-Xin LI*2, \\ Kui MA*1, Nan ZHENG*1 and Zhang YAN*1 \\ ${ }^{*}$ State Key Laboratory of Electrical Insulation and Power Equipment, School of Electrical Engineering, \\ $X i$ 'an Jiaotong University, Xi'an, Shaanxi 710049, China \\ ${ }^{*}$ School of Material Science and Engineering, Xi'an Jiaotong University, Xi'an, Shaanxi 710049, China
}

(Received July 13, 2006, Accepted February 10, 2007)

Ceramic material has been widely used as insulator in vacuum. Their high hardness and brittle property brings some difficulty in the application. A new kind of machinable ceramic was invented recently. The ceramic can be machined easily and accurately after being sintered, which provides the possibility of making the insulator with fine and complicated configuration. The paper studies its surface insulation performance and flashover phenomena under pulsed excitation in vacuum. The ceramic samples with different crystallization parameters are tested under the vacuum level of $10^{-4} \mathrm{~Pa}$. The machinable ceramic behaves better surface insulation performance than comparative the $\mathrm{Al}_{2} \mathrm{O}_{3}$ and glass sample. The effect of crystallization level on the trap density and flashover current is also presented. After flashover shots many times, the surface microscopic patterns of different samples are observed to investigate the damage status, which can be explained by the thermal damage mechanism.

\section{Introduction}

Ceramic materials possess good performances in the condition of high temperature and high electric field, and have been applied widely as the insulator in vacuum for a long time. Alumina ceramic is a typical and practical kind of electrotechnical porcelains in vacuum, which is popularly accepted. However, the alumina insulator has to be molded and after it is sintered its shape is difficult to be changed further. With the vacuum system being expanded to broader field, the request of the compact size makes the shape of insulator to be more and more complicated. The hard and brittle properties of the alumina ceramic always bring some troubles to the insulation structure of the vacuum system. If the insulator can be machined like metal, this problem could be solved easily.

Recently a novel machinable ceramic is produced ${ }^{1)}$, which provides the possibility that produces the vacuum insulator with more nice profile. Lower melting temperature and better drilling performance is obtained than present similar material (e.g. Macor ${ }^{\mathrm{TM}}$ glass). And the empirical technics of further crystallization ensure higher strength. This kind of machinable ceramic is composed of $\mathrm{SiO}_{2}-\mathrm{B}_{2} \mathrm{O}_{3}-\mathrm{Al}_{2} \mathrm{O}_{3}-\mathrm{ZnO}-\mathrm{MgO}-\mathrm{F}$ system and alkali metal oxides, and $\mathrm{SiO}_{2}$ is the main component. It is a kind of glass ceramic with the structure like mica, with lower melting temperature $\left(1250 \sim 1300^{\circ} \mathrm{C}\right)$ and low glass transition temperature $\left(650^{\circ} \mathrm{C}\right)$. For the transition temperature is lower than the temperature in the cutting area $\left(700 \sim 800^{\circ} \mathrm{C}\right)$ when the ceramic material being machined, the ductile-mode machinability of the glass ceramic is implemented in general machining equipment by universal cutter ${ }^{2}$. During the process of the machin-

* Presented at ISDEIV 2006, Matsue, Japan, September 25-29, 2006

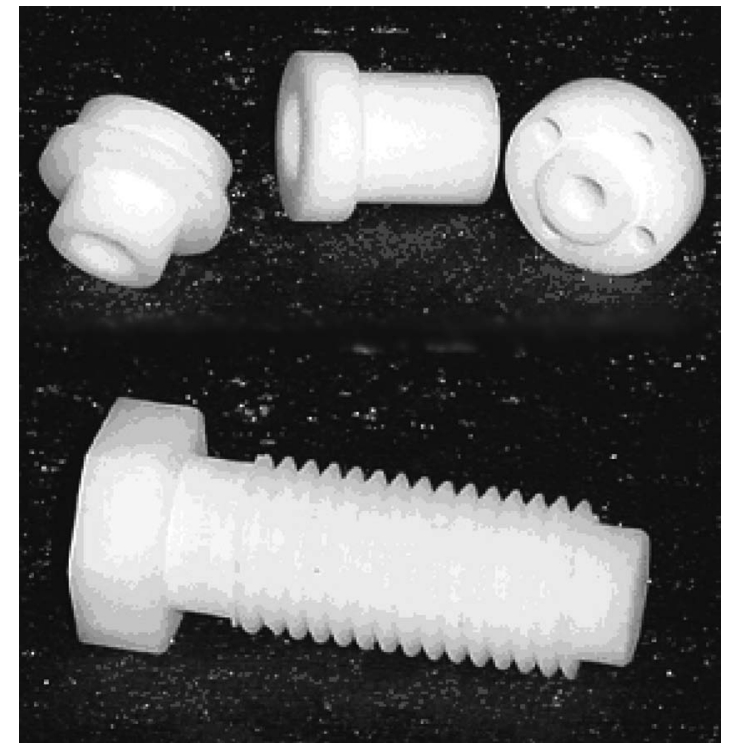

Fig. 1 Glass ceramic workpieces made by the means of machining.

ing, the craft requests of cutting the machinable ceramic are most similar to the parameters of the metal. It is astonished that the continuous cutting chip can be obtained at different cutting speed. After the machining procedure, the glass ceramic can be crystallized further at a higher temperature $\left(\sim 750^{\circ} \mathrm{C}\right)$, through which the higher flexible strength $(210 \mathrm{MPa})$ can be derived ${ }^{3}$. This value approximates the flexible strength of alumina with the purity of $80 \%$. The photographs of some glass ceramic workpieces produced by the means of the machining are as shown in Fig. 1. The surface of the machinable glass ceramic is very dense, which is another good characteristic for being used in the vacuum system.

There is a widely accepted theory ${ }^{4-8)}$ that the flashover 
Table 1 Basic dielectric property of the samples

\begin{tabular}{cccccc}
\hline \hline Samples & $\begin{array}{c}\text { Dimensions } \\
(\mathrm{mm})\end{array}$ & $\begin{array}{c}\text { Volume } \\
\text { Resistivity } \\
\left(\rho_{\mathrm{v}}\right) \\
(\Omega \cdot \mathrm{cm})\end{array}$ & $\begin{array}{c}\text { Surface } \\
\text { Resistivity } \\
\left(\rho_{\mathrm{s}}\right)\end{array}$ & $\varepsilon r$ & $\begin{array}{c}\text { Crystallization } \\
\text { Conditions }\end{array}$ \\
\hline $\mathrm{Al}_{2}\left({ }^{\circ} \mathrm{C}\right) / t(\mathrm{~h})$
\end{tabular}

phenomena in vacuum initiate from the field emission at CTJ (Cathode Triple Junction), pass through the process of the SEEA (Secondary Electron Emission Avalanche) and complete in desorption gas layer. The SEEA is regarded as a major reason of outgassing. A recent report ${ }^{9)}$ suggested that the crystallization craft of the alumina ceramic has latent effect on the trap density, SEEA process and flashover voltage. Obviously, the influence of craft parameters also has direct effect on the capacity of machinable ceramic absorbing gas molecule. Thus, there is maybe a complicated mechanism of the craft parameters influencing the flashover. This paper investigated the surface insulation performance of the machinable glass ceramic under pulsed voltage in vacuum, and compared it to the alumina ceramic and normal glass. The thermal damage mechanism of the machinable ceramic was also discussed.

\section{Samples and Experimental arrangement}

\subsection{Samples}

The three circular machinable ceramic samples with same components and different crystallization conditions (crystallization temperature and crystallization time, $T_{\mathrm{c}}$ $/ t$ ) are used in the experiment, and the alumina and normal glass samples are also investigated as the contrast. The dimensions, basic electrical parameters (measured via an high resistance meter (ZC-36) and a high voltage bridge (ANDO TR-10C)) and crystallization parameters are listed in Table $\mathbf{1}$.

\subsection{Experimental Setup}

Each sample is placed on an organic glass substrate plate, and two stainless steel (SS) electrodes with the shape of the frustum of a cone are butted on it with a gap spacing of $2 \mathrm{~mm}$. Each electrode is fixed with a polytetrafluoroethylene (PTFE) brace and pressed by the springs, as shown in Fig. 2.

All samples are carefully cleaned with absolute acetone, alcohol and distilled water in an ultrasonic cleaner. The samples have also been dried in atmosphere for more than 2 hours at about $200^{\circ} \mathrm{C}$ before experiments.

A one-stage Marx generator with a waveform of $\sim 0.4 / 2.5 \mu$ s while no load is constructed is described in Fig. 3. One electrode butted to the sample is connected to its output, and the other to the ground through a 25.6 $\mathrm{m} \Omega$ current viewing resistor (CVR). The applied voltage is recorded by a 4-channel digital oscilloscope (Tektronix TDS3014, $100 \mathrm{MHz}$ bandwidth, $1.0 \mathrm{G} \mathrm{Sa} / \mathrm{s}$ sampling rate) through a HV probe (Tektronix P6015A, 1000:1

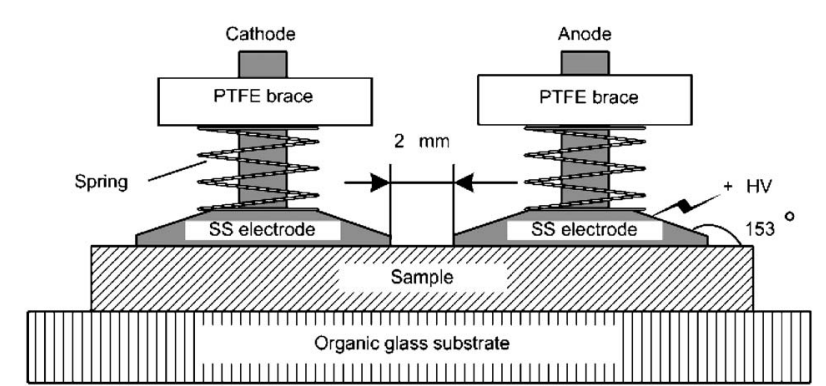

Fig. 2 Layout of the electrodes system.

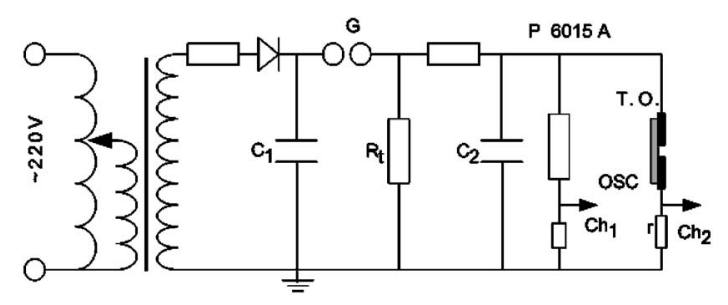

Fig. 3 Experimental circuit.

voltage dividing ratio, $75 \mathrm{MHz}$ bandwidth) and the current was measured via the CVR. The sample was mounted in a vacuum and lighttight chamber with a rear port connected with a turbo molecular pump system allowing work down to $<5 \times 10^{-4} \mathrm{~Pa}$. The chamber was equipped with 3 quartz view ports. The side and main view ports lay at an angle of 30 degrees. The two optical devices were organized around axes converging at the center of sample. All experiments were performed in the experimental chamber.

\section{Experimental results}

\subsection{Waveforms of applied voltage and current}

Figure 4 shows the typical voltage and current waveforms while applying pulse excitation across machinable ceramic in vacuum. Figure 4(a) shows the waveforms while no discharge occurred at a low voltage. There is a fluctuation region appeared at the beginning of current waveform in Fig. 4(a). We considered it as interference aroused by the geometric capacitor between the two electrodes. The oscillation of the interference current may be resulted from the weak current for no match impedance in the circuit. Figure 4(b) displayed the waveforms under a higher applied voltage. We can observe that the current begin to climb up when the applied voltage collapse suddenly, which is the waveforms of flashover occurring in the tail of the pulse voltage. When voltage waveform begin to fluctuate with decreasing amplitude at the breakdown point, and the current descend from the peak gradually with some little oscillation.

\subsection{Performance of the flashover across the samples}

Firstly, we increase the charging voltage of the Marx generator step by step. And then, after the flashover become stable, the charging voltage is stepped down. At the same voltage level of the every step, 10 times shots are applied, and the average values of the maximum applied voltage and the maximum current are recorded, as 


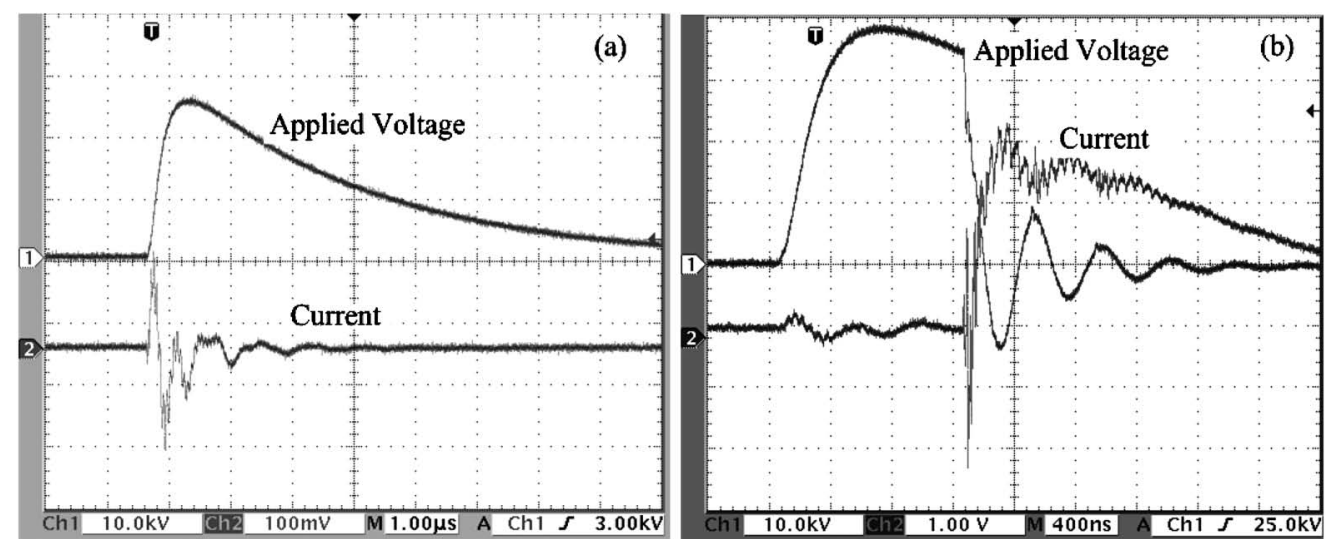

Fig. 4 Typical waveforms of excitation by pulse on the surface of mechinable ceramic (a) while no discharge (b) while discharge.

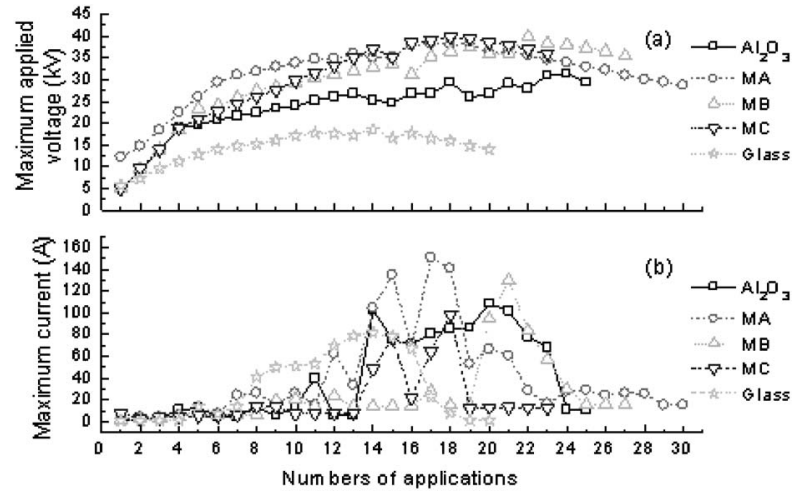

Fig. 5 Voltage and current curves under pulse voltage (a) Maximum applied voltage (b) Maximum current.

shown in Fig. 5.

In the experiment, we define 3 characteristic values to indicate the surface insulation strength of each sample: the low-probability flashover voltage $V_{\mathrm{L}}(\leq 10 \%)$, the maximum withstand voltage $V_{\mathrm{M}}$, and the residual withstand voltage $V_{\mathrm{R}}$. With the stepped increment of the applied voltage, some infrequent flashover events will occur. Generally, after this time occasional flashover event during ten shots, the flashover will not take place in spite of more shots at the same voltage level. The peak values of the applied voltage (include less than 1 time flashover) during the ten time shots are averaged to be the low-probability voltage $\left(V_{\mathrm{L}}\right)$. When the voltage exceeds a certain level, the surface breakdown occurs 10 times for ten shots. We record the peak values of the ten applied voltage and define the average value of them as the maximum withstand voltage $\left(V_{\mathrm{M}}\right)$. After many times ( $\geq 10$ times) surface breakdown, the flashover takes place invariably in spite of several step decrement of the applied voltage. After the voltage drops to $V_{\mathrm{R}}$ (average of the ten applied voltage peak), the sample can withstand the surface shot without flashover. The surface insulation performance of all samples is summarized in Table 2.

\subsection{Microscopic patterns of the surface structure}

Figure 6 shows the optical micrographs at the edge of the cathode on the surface of the samples, which is ac-
Table 2 Surface insulation performance of the samples

\begin{tabular}{c|c|c|c}
\hline \hline Sample & $V_{\mathrm{L}}(\mathrm{kV})$ & $V_{\mathrm{M}}(\mathrm{kV})$ & $V_{\mathrm{R}}(\mathrm{kV})$ \\
\hline $\mathrm{Al}_{2} \mathrm{O}_{3}$ & 23.92 & 34.40 & 31.43 \\
$\mathrm{Glass}$ & 11.18 & 17.61 & 14.86 \\
$\mathrm{MA}$ & 34.78 & 38.22 & 30.12 \\
$\mathrm{MB}$ & 27.58 & 39.89 & 38.40 \\
$\mathrm{MC}$ & 35.12 & 39.72 & 39.46 \\
\hline
\end{tabular}

quired by the microscope (OLYMPUS BX-51).

The area near the edge of electrode on the surface of the sample is always damaged more badly by surface flashover. The ablating tracks could be even easily observed by the naked eye. The obvious dark area in Fig. 6(a1) is produced by the flashover on the surface of $\mathrm{Al}_{2} \mathrm{O}_{3}$. Via the high power lens, it is found that the crystal grain of $\mathrm{Al}_{2} \mathrm{O}_{3}$ is distorted, shown in Fig. 6(a2).

The macroscopic and the microscopic surface of the normal glass are as shown in Fig. 6(b1) and (b2) respectively. We can found some distinct cracks in the damaged area. And we also found many thin stripes extending from the cracked area.

The dark spot in the Fig. 6(c1) shows the macroscopic pattern damaged by the flashover on the surface of the machinable ceramic (MA). Many evenly distributed oblique lines can be also found in Fig. 6(c1), which is produced by the machining. Fig. 6(c2) displays the microscopic surface of the sample MA. Because of the wavy surface of the MA, focusing is difficult ranged in the whole field of vision under the high power lens. But we have known that those oblique regular stripes are machining tracks. In the Fig. 6(c2), We find many micro grains in the clear area between the two machining tracks via high power lens. But, it is difficult to discriminate the tracks damaged by the flashover in the microscopic graph of the Fig. 6(c2).

\section{Analysis and discussion}

\subsection{Summary of the flashover data}

According to the experiment results, we found that in vacuum the insulation performance of machinable ceramic is better than that of the alumina, and far higher 

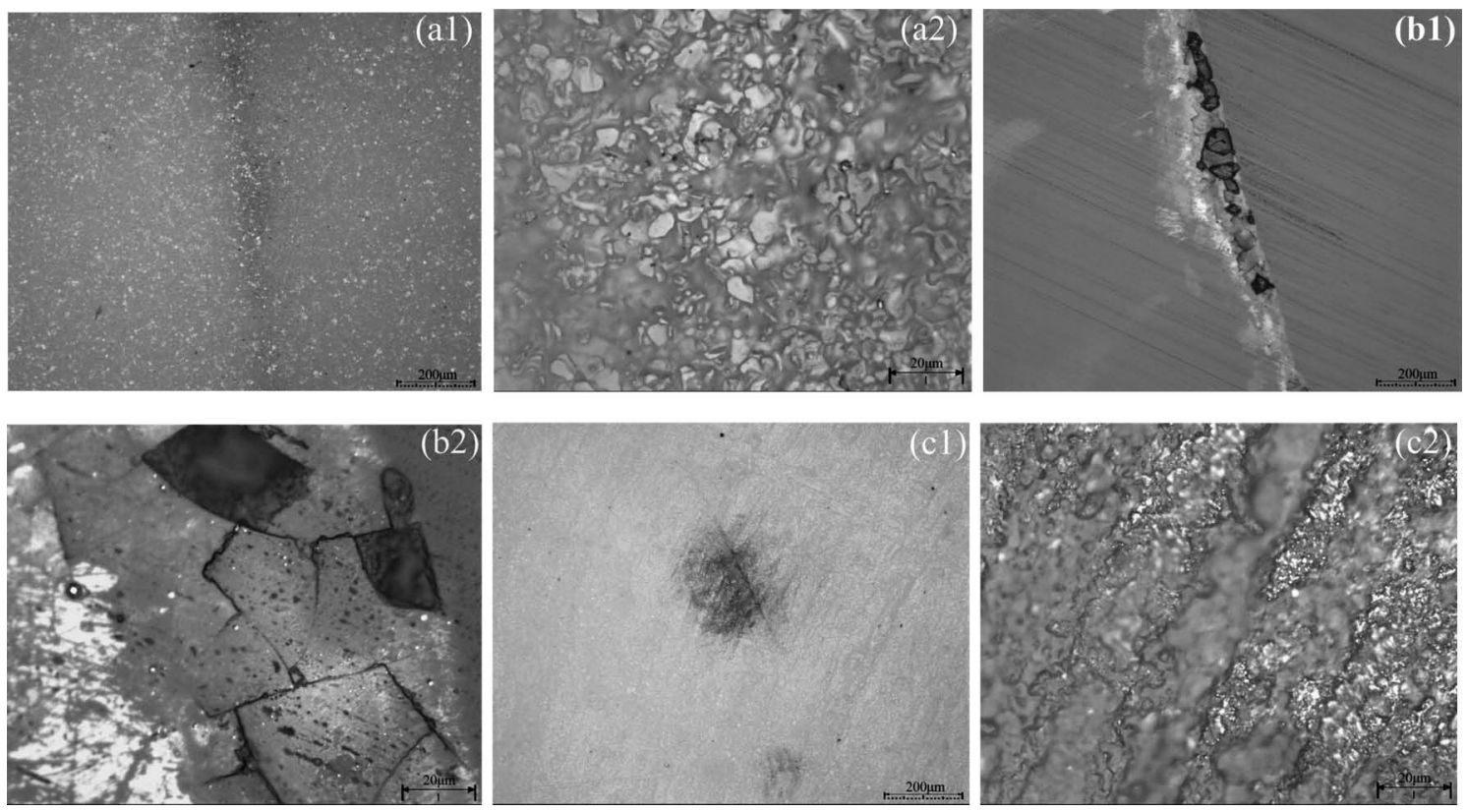

Fig. 6 Optical micrographs at the cathode edge on the surface of $\mathrm{Al}_{2} \mathrm{O}_{3}(\mathrm{a} 1$, a2); normal glass (b1, b2) and machinable ceramic (MA) (c1, c2).

than that of the normal glass. The low-probability flashover voltage $\left(V_{\mathrm{L}}\right)$ of the machinable ceramic (MA and $\mathrm{MC}$ ) even exceeds the experimental results of the glass ceramic (Macor ${ }^{\mathrm{TM}}$ with the permittivity of 5.8) reported in $^{10)}$ under the similar excitation.

In the Table 2, it can be noted that the difference between the $V_{\mathrm{L}}$ and $V_{\mathrm{M}}$ of the sample $\mathrm{MB}$ is larger than that of MA and MC, which may be attribute to occasional factors such as the dust, micro spine on the electrodes, asymmetry surface and so on.

The process parameters during the procedure of preparation, especially crystallization temperature, have obvious effect on the surface insulation strength, which can be indicated by a rather lager difference between $V_{\mathrm{R}}$ and $V_{\mathrm{M}}$ of the sample MA. Based on the results, we can infer that the crystallization process on the surface has reach saturation in 2 hours (as shown in Table 1). Thus, the crystallization degree is more sensitive to the temperature, which can lead to the difference of the insulation strength under the pulse voltage. This experiment results are agreed with the phenomena reported in ${ }^{9}$.

\subsection{Surface damage of the surface and charge injection}

The electric field at the edge of the electrodes is generally strongest $\left(\sim 10^{7} \mathrm{~V} / \mathrm{m}\right.$ at the cathode triple junction) ${ }^{11)}$ in the area between the two electrodes. Under the strong electric field, the injection phenomena will occur ${ }^{12)}$. Though the space charge injected from the electrode can counteract part of the applied voltage, the ionic current would be enhanced by the increasing applied voltage. In the crystal the ionic current is dominant, and the ionic conductivity induced by the unique carrier can be described in Equation (1).

$$
\sigma=A \exp \left(-\frac{B}{T}\right)
$$

Where $\sigma$ is the ionic conductivity; A is a constant; $\mathrm{B}$ is the constant related to the activation energy (estimated

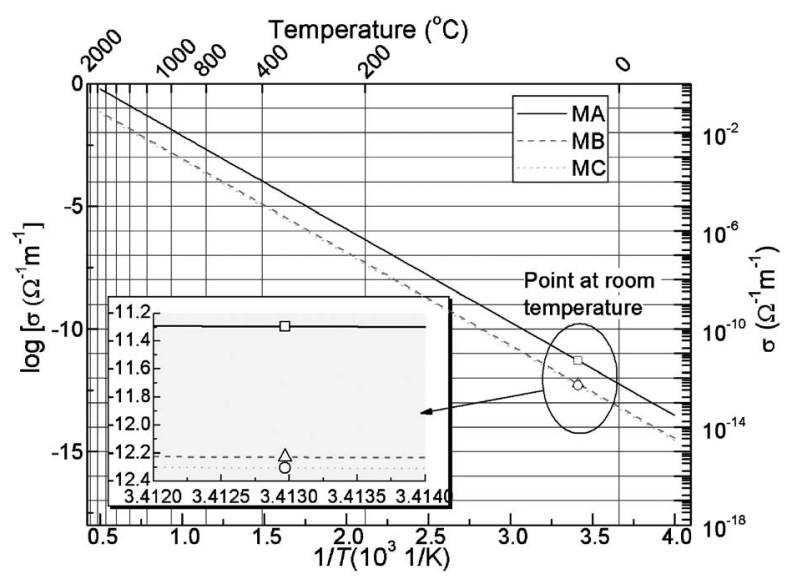

Fig. 7 Relation between ionic conductivity and the temperature for the machinable ceramic MA, MB and MC.

by the value of the white mica, 8750). Assuming only one kind of ions involved in the behavior of ions transferring, neglecting the intrinsic excitation, the ionic conductivity of the machinable ceramic near the melting point can be estimated by Equation (1) according to the value at the room temperature, the rough relation between the temperature and conductivity is shown in Fig. 7.

It can be observed that the conductivity near the melting point of about $1000^{\circ} \mathrm{C}$ is about the order of $10^{-3}$ $\sim 10^{-2} \Omega^{-1} \mathrm{~m}^{-1}$, by which we can estimate ${ }^{11)}$ that the ionic current can attain the levels from $10^{-1}$ to $10 \mathrm{~A}$ when the flashover occurs invariably (the applied voltage is about $38 \sim 40 \mathrm{kV}$ as shown in Table 2). When the current passes through a tiny spot, the local material at the spot can be melted, which maybe lead to the further enhancement of the injection phenomena. The photographs in Fig. 6 are evidences of strong injection.

4.3 Surface condition and flashover current

If defining the maximum flashover current of MA, MB 
and MC sample as $I_{\mathrm{mA}}, I_{\mathrm{mB}}$ and $I_{\mathrm{mC}}$, we can find the relation of $I_{\mathrm{mA}}>I_{\mathrm{mB}}>I m_{\mathrm{C}}$ in the Fig. 5(b), which is due to the difference of the surface condition. The crystallization temperature of the sample MA is lower than that of $\mathrm{MB}$ and $\mathrm{MC}$, and the crystallization grade is not enough. Thus, there are more non-crystalline microstructure and amorphous impurities in the material, which can form more trapping centers. These trapping centers could cause more surface states, which are the likely reason that the MA has lower surface resistivity, higher permittivity and lager flashover current.

\section{Conclusions}

Compared with conventional alumina ceramic and glass, the machinable glass ceramic possesses satisfied surface insulation strength. Its electrical performance is sensitive to its crystallization parameters such as the temperature and time. It also possesses the fairish ability of anti ablating, and can keep partial surface insulation strength after undergoing several flashover events. The further work, the effects of different parameters on the insulation performance such as the trapping parameters, dielectric properties, roughness, etc., will be reported in the future.

\section{Acknowledgment}

This work was supported by the National Natural Science Foundation of China (Grant No. 50577054), by the New Century Excellent Talents in University of MOE, China (NCET-04-0943) and by the Doctoral Foundation of Xi'an Jiaotong University (DFXJTU2004 $-03)$.

\section{References}

1) X. P. Ma, G. X. Li, L. Shen and Z. H. Jin: J. Am. Ceram. Soc., 86 (2003) 1040.

2) X. P. Ma, G. X. Li and L. Shen: JOURNAL OF INORGANIC MATERIALS, China, 19 (2004) 48.

3) X. P. Ma, G. X. Li and L. Shen: JOURNAL OF INORGANIC MATERIALS, China, 15 (2000) 365.

4) R. A. Anderson and J. P. Brainard: J. Appl. Phys., 51 (1980), 1414.

5) A. Watson: J. Appl. Phys., 38 (1967) 2019.

6) H. Brettschneider: IEEE Trans. EI., 23 (1988), 33.

7) W. B. Zhao, G. J. Zhang, L. Xie and Z. Yan: Proc. 8th IEEE Int. Conf. on Solid Dielectr., Toulouse, France, 2004, p. 888.

8) Y. S. Liu, G. J. Zhang, W. B. Zhao and Z. Yan: J. Applied Surface Science, 230 (2004) 12.

9) C. R. Li, L. J. Ding, J. Z. Lv, Y. P. Tu and Y. C. Cheng: IEEE Trans. Dielectr. Electr. Insul, 13 (2006) 79.

10) A. S. Pillai and R. Hackam: J. Appl. Phys., 56 (1983) 1374.

11) Y. Yamano, S.Ito, H. Okubo: IEEE Trans. Dielectr. Electr. Insul., 9 (2002) 173.

12) G.J. Zhang, W. B. Zhao and Z. Yan: IEEE Trans. Dielectr. Electr. Insul., 11 (2004) 198. 